\title{
C-reactive protein in spinal surgery: more predictive than prehistoric
}

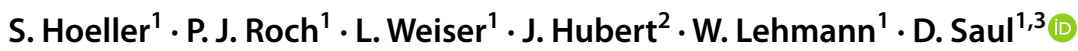

Received: 26 October 2020 / Revised: 10 January 2021 / Accepted: 18 February 2021 / Published online: 7 March 2021

(c) The Author(s) 2021

\begin{abstract}
Purpose In spinal surgery, surgical site infections (SSI) after dorsal spondylodesis lead to severe short- and long-term complications. Despite various clinical and serological evidence, the detection of a postoperative SSI remains crucial. In this retrospective cohort study, we determined the prognostic value of C-reactive protein (CRP) kinetics after open reduction and dorsal spondylodesis in the development of a SSI.

Methods We retrospectively analyzed 192 patients from 2016 to 2018 undergoing open reduction and dorsal spondylodesis with and without SSI for 20 days at a level-I trauma center and assessed their serological and clinical characteristics.

Results On day 7 and 8 after surgery, patients who developed a SSI displayed significantly higher CRP levels. A second peak after the initial maximum of CRP and a restricted failure to decline as well as a maximum CRP of more than $225 \mathrm{mg} / 1$ predict an infectious complication with a sensitivity of $92.9 \%$, and a specificity of $78.2 \%$. A binary logistic regression leads to $85.7 \%$ and $69.7 \%$, respectively. A one-phase decay exponential regression can predict $75.6 \%$ of the variance after the initial peak of CRP.

Conclusion Our study demonstrates a high value of postoperative CRP kinetics in SSI detection after dorsal spondylodesis. Moreover, we observed typical CRP levels with a specific course as indicative predictors that may facilitate an early SSI detection in clinical practice.
\end{abstract}

Keywords C-reactive protein $\cdot$ Spinal surgery $\cdot$ Revision surgery $\cdot$ Dorsal spondylodesis $\cdot$ Surgical site infection

\section{Introduction}

Open reduction with dorsal spondylodesis is an established standard operation in spinal surgery which was performed over 463,200 times in the U.S. in 2014 [1, 2]. Indications range from degenerative spondylolisthesis with instability to traumatic B-type fractures with further need to ventral stabilization [3,4]. A severe complication after spondylodesis is the occurrence of a surgical site infection (SSI). Devastating consequences for the patient in the short- and long-term let

S. Hoeller and P. J. Roch has contributed equally to this work.

D. Saul

Dominik.Saul@med.uni-goettingen.de

1 Department of Trauma, Orthopedics and Reconstructive Surgery, Georg-August-University of Goettingen, Robert-Koch-Straße 40, 37075 Goettingen, Germany

2 Department of Orthopedics, University Medical Center Hamburg-Eppendorf, Hamburg, Germany

3 Kogod Center On Aging and Division of Endocrinology, Mayo Clinic, Rochester, MN 55905, USA alone resulting socio-economic burden lead to the development of strategies to prevent SSI in patients undergoing spine surgery [5, 6]. Despite these widely accepted and attended routines like antibiotic prophylaxis and wound irrigation in prolonged spinal surgery, the rate of early SSI after dorsal spondylodesis has been assessed around 1.9-11.9\% [7-11], whereas comparable orthopedic routine operations report lower values around $2.2 \%[12,13]$. In virtue of these alarming data, several systematic reviews and meta-analyses have attempted to develop multifactorial risk stratification systems to assess the risk for the individual patient to acquire a SSI [6, 14-16].

CRP was shown to be superior to both ESR and WBC in terms of assessing a SSI $[17,18]$. The actual dilemma regarding serologic parameters is the missing "normal" course of CRP values after dorsal spondylodesis to be distinguished from a pathological course indicating an infection and necessity for revision. Although observing the CRP course has been a useful tool for decades to indicate either normal or pathological processes, a distinctive value or cut-off following the operative procedure after which an 
infection seems most likely to occur, has not been established so far.

Thus, the overall objective of this study was to help develop an algorithm leading to earlier débridement and targeted antibiotic therapy, which in turn could assist to cure these patients, before the SSI leads to implant removal and the abovementioned devastating side effects.

\section{Methods}

\section{Patients}

From 2016 to 2018, we retrospectively analyzed 192 patients undergoing open reduction and dorsal spondylodesis at a level-I trauma center in Germany. Indications were degenerative spondylolisthesis as well as traumatic fractures. The study was approved by the local ethics committee (IRB number 16/7/19). All research was performed in accordance with the principles expressed in the Declaration of Helsinki, all study participants voluntarily attended the study and gave informed consent.

Patient-related criteria (age and sex) were recorded. Additionally, assessed parameters were C-reactive protein (CRP), white blood cell count (WBC), hemoglobin ( $\mathrm{Hb}$ ) and thrombocytes. Whether the cause of operation was traumatic or degenerative, the number of bridged segments as well as the region of operation (cervical, thoracic or lumber) was recorded.

Blood serum was collected in the morning of the respective day, consistently before surgery. In every operation, preoperative intravenous antibiotics was applied one hour before surgery (usually cefazolin $2 \mathrm{~g}$, clindamycin $600 \mathrm{mg}$ in case of penicillin allergy; topical intrawound application of vancomycin powder was not performed). Drains were routinely removed on the second day after surgery. The wound was inspected every two days after surgery. Blood samples were taken on average every second day (mean of 0.40 samples/day) and only in the stationary setting until the patient was discharged from hospital.

The patients were divided into two groups: an "infection" group and a "non-infection" group. Patients were included into the "infection" group if a bacterium was detected during revision surgery after multiple aerobic and anaerobic tissue biopsies were cultured (at least five, incubation for at least three weeks) and histopathology was obtained according to the recommendations of the AAOS and Dowdell et al. [6, 19]. From the day after this operation, the CRP levels were excluded from measurements since a second peak after revision surgery would falsify further calculation.

\section{Inclusion criteria}

- Patients $>18$ years.

- Open reduction and dorsal spondylodesis in the cervical, thoracic or lumbar spine from 01/01/2016 until 12/31/2018.

- One of three senior operators had performed the operation.

\section{Exclusion criteria}

- Patients $<18$ years.

- Open fractures.

- Tumorous diseases.

- A priori infection of the spine.

- Manifested infection prior to surgery or inflammatory disease.

- Incomplete patient recordings.

\section{Determination of peak value}

A postoperative peak was defined as the earliest CRP level increase (normal: $<5 \mathrm{mg} / \mathrm{l}$ ) after the operation which was preceded and followed by lower CRP values. A second peak was defined as-after a first postoperative peak occurred-another CRP value which was preceded and followed by lower CRP values.

\section{Postoperative kinetics}

A postoperative peak was determined and recorded in patients with an uncomplicated course and no infection. CRP data from these patients were displayed as a scatter plot. Subsequently, CRP values were normalized as percentage of the peak value and the peak normalized on the number of days after the peak. One-phase decay exponential regression was used to approximate these raw data.

A failure to decrease after the (first) postoperative peak was assessed for the third and fourth day. According to the calculated exponential one-phase decay (see below) a decline on day 3 and 4 was determined as $52.7 \%(+15 \%$ threshold, i.e., $67.7 \%)$ and $44.8 \%(+15 \%$ threshold, i.e., $59.8 \%)$ of the peak value, respectively.

The resulting predictive test which we conducted was defined positive if:

1) The existence of a second peak was recognized or

2) The existence of a second peak or a failure to decline occurred. and-additionally in the second measurement- 
3) The maximum CRP outvalued a certain cut-off

Resulting sensitivity, specificity, positive and negative predictive values are reported.

\section{Statistics}

For a statistical power of $0.95(\alpha$ error $=0.05)$ and to detect medium effect sizes $(|\rho|=0.3)$, a sample size of 134 was needed. If two groups (infection and non-infection) were normally distributed was assessed by D'Agostino-Pearson-Test. If so, Student's two-tailed t test was performed. Otherwise, Mann-Whitney test was performed and shown accordingly. In group comparison, Fisher's exact test was performed. Differences among both groups in CRP kinetics have been assessed by Wilcoxon signed rank test. Binary logistic regression model was used to find predictors for an infection. Within the frame of an exploratory study predictors were chosen by forward inclusion [20]. Multiple linear regression was used to detect predictors elevating CRP values. In the reoperation-group, all values after the second operation were excluded.

Statistical analysis was conducted with GraphPad Prism 8.02 (GraphPad Software, San Diego, USA), SPSS Statistics software version 26.0 (IBM SPSS Inc., Chicago, IL, USA) and R 4.0.0 (The R Foundation for Statistical Computing, Vienna, Austria). If not differentially stated, overall, mean \pm standard deviation is presented.

\section{Results}

\section{Cohort characteristics}

Hundred and seventy-eight patients were included in the non-infection group and 14 individuals in the infection group. Age in control-group $(67.30 \pm 15.73$ years $)$ and infection group (67.64 \pm 10.13 years) did not differ significantly ( $p=0.690$, Mann-Whitney test). Sex among both groups (control: $50.6 \%$ male; infection: $71.4 \%$ male) was not significantly different ( $p=0.170$, Fisher's exact test). The region and underlying reason of operation did not differ among groups (Suppl. Table 1). The incidence of SSI differed depending on the number of operated segments.

Due to logistic reasons, the CRP measurements were not strictly performed on a daily or weekly basis. In average, we measured the CRP every second day (0.40 times per day). To control for selection bias, the average amount of CRP measurements per day was assessed in each group, and no difference was detected (mean non-infection: 0.40, infection: $0.42, p=0.706$, Mann-Whitney test).
Patients were discharged after $10.3 \pm 4.1$ days (non-infection group: $9.7 \pm 3.6$ days, infection group: $18.0 \pm 2.2$ days, $p<0.001)$.

\section{Kinetics of C-reactive protein}

Eighty-two out of 178 patients in the non-infection group (46.1\%) and 9 of 14 patients in the infection group (64.3\%) had preoperatively CRP values above reference $(\geq 5 \mathrm{mg} / \mathrm{l})$. The mean preoperative CRP values were $20.25 \mathrm{mg} / 1$ $( \pm 34.35)$ and $26.2 \mathrm{mg} / \mathrm{l}( \pm 30.45)$, respectively $(p=0.250$, Mann-Whitney test).

The maximum CRP value was reached on day 3 with $134.89 \mathrm{mg} / \mathrm{l}( \pm 64.22)$ in the non-infection group. In the infection group, the maximum CRP value was reached on day 2 with $215.38 \mathrm{mg} / \mathrm{l}( \pm 69.05, p=0.894)$.

The only significant difference between the noninfection and infection group was days $7(66.5 \pm 48.3$ vs. $131.4 \pm 79.7 \mathrm{mg} / \mathrm{l}$, respectively) and $8(55.4 \pm 45.5 \mathrm{vs}$. $121.0 \pm 57.2 \mathrm{mg} / \mathrm{l}$, respectively) (day 7 adjusted $p=0.044$ and day 8 adjusted $p=0.007$, Holm-Sidak method, Fig. 1). Relating the CRP to the maximum CRP (which is reached on day 3 or 2 after the operation), in the non-infection group, a steady decline from day 3 on until day 8 was observed, whereas the infection group did not present this steady deterioration (Fig. 2).

Nonetheless, the decline in the non-infected group did not follow a linear regression $\left(R^{2}=0.4423\right)$ nor exponential regression (one-phase decay, $R^{2}=0.4805$ ) when the maximum was measured individually for each patient. After adjusting the maximum CRP on day 0 and subsequently adjusting the following CRP values to this day 0 maximum, an exponential regression following a one-phase decay was set with a satisfying approach for the non-infection group, but not the infection group $\left(y=0.7537 \times \mathrm{e}^{(-0.3246 \times \mathrm{x})}+0.242\right.$ $3 ; R^{2}=0.7562$, Fig. 2a, b).

\section{Diagnostic value of "day 2" and "day 3" CRP}

Since the peak value of postoperative CRP was seen on day 2 and 3 in the non-infection group, different cut-off values were tested with regard to their prognostic value. A cut-off value of $200 \mathrm{mg} / \mathrm{l}$ for day 2 resulted in a sensitivity, specificity, positive predictive value (PPV) and negative predictive value (NPV) of $75 \%, 86 \%, 6.5 \%$ and $98 \%$, respectively. A cut-off value of $100 \mathrm{mg} / \mathrm{l}$ for day 3 resulted in $75 \%, 38 \%$, $20 \%$ and $92 \%$, respectively (Suppl. Figure $1 \mathrm{a}-\mathrm{d}$ ).

\section{Determinants of peak CRP}

In the non-infection group, 175 out of 178 had a postoperative peak (98\%), while in the infection group, 14 of 14 displayed a peak (100\%). Next, determinants of a higher 


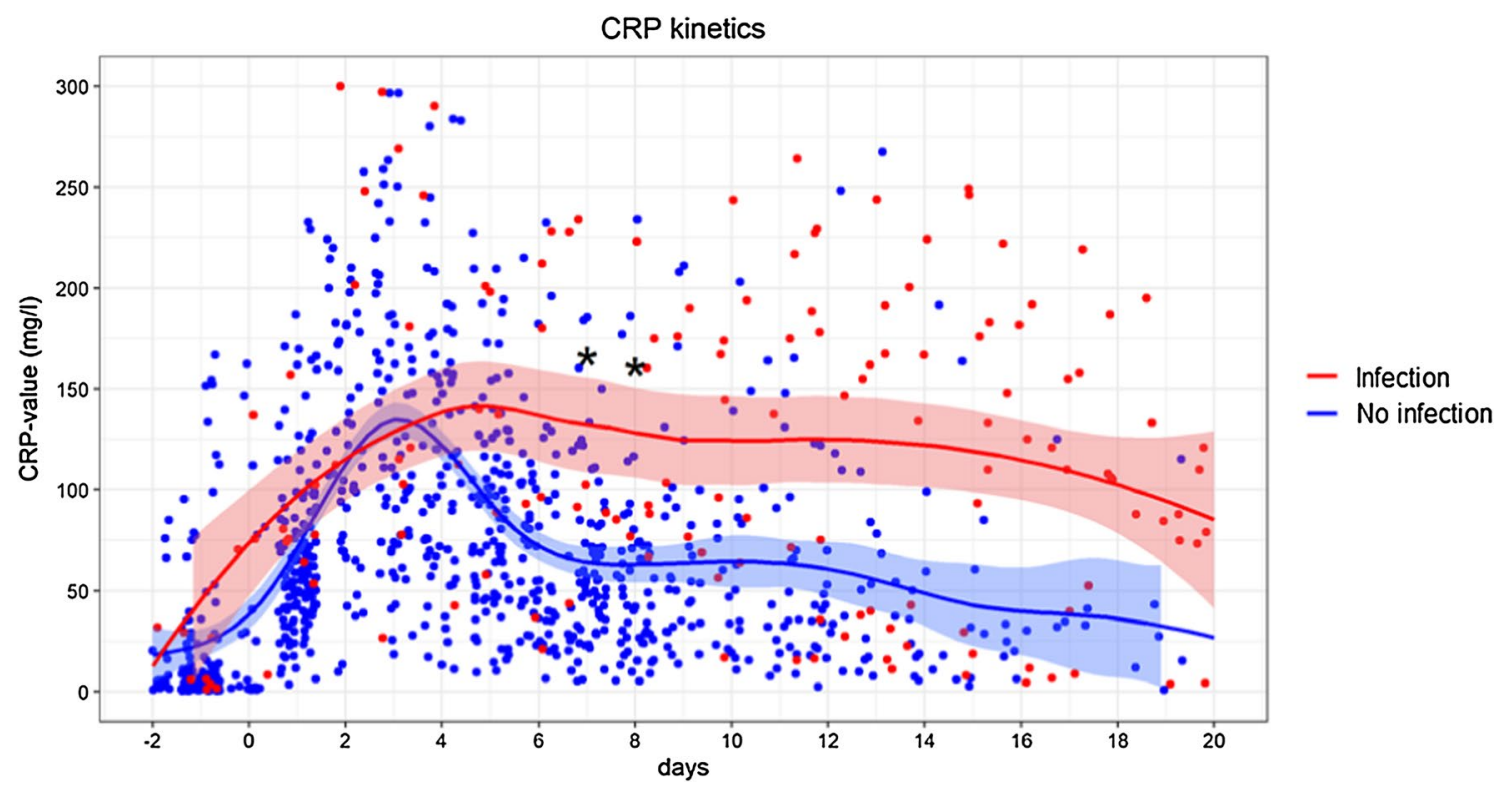

Fig. 1 Course of C-reactive protein levels in cohorts with and without infection CRP levels were determined 3 days before as well as on the day of surgery with follow-up measurements on every second day. The peak of CRP was reached on day 3 in the non-infection and on day 2 in the infection group. The statistically significant differ- ences among both groups were detected on day 7 and 8 , on which the non-infection-group had lower values compared to the infection group (Holm-Sidak method, day 7: $p=0.044$, day 8: $p=0.007$ ). Mean \pm SEM

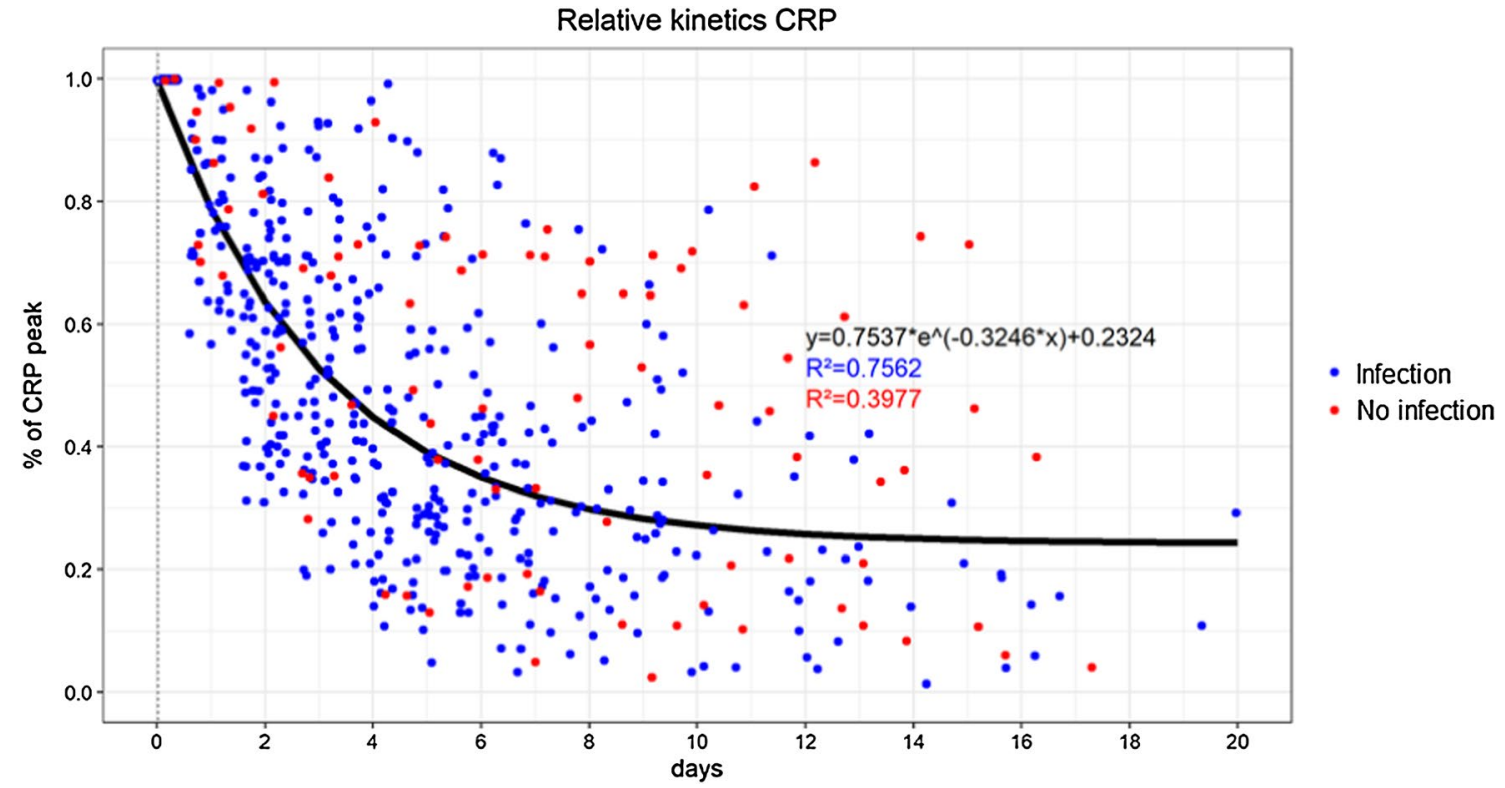

Fig. 2 Kinetics of CRP in relation to the day of peak CRP in the noninfection (blue) and infection (red) group. Setting the maximum of CRP value on day 0 , the course of CRP followed a one-phase decay exponential regression in the non-infection group (red, $\mathrm{R}^{2}=0.7562$, half-life of 2.135 days). This approximation was not adequate in the infection group (blue, $\mathrm{R}^{2}=0.3977$ ) peak CRP were sought. Therefore, multiple linear regression identified age $(p=0.002)$, number of addressed segments $(p=0.009)$ as well as preoperative CRP $(p=0.021)$ as determinants for regression analysis. The biggest association with maximum CRP, regarding to $\beta$-coefficient, was caused by age (Table 1). Binary logistic regression for an infection based on these variables, however, did not yield in a statistically significant prediction model $\left(R^{2}=0.078\right)$. 
Table 1 Multiple linear regression analysis reveals a significant relation between age, preoperative CRP and number of addressed segments, but not sex or region

\begin{tabular}{lll}
\hline Multiple regression & $p$-value & $\begin{array}{l}\text { Standardized } \beta \\
\text { coefficients (SE) }\end{array}$ \\
\hline Age & $* *(0.002)$ & 0.244 \\
Number of addressed segments & $* *(0.009)$ & 0.207 \\
Preoperative CRP & $*(0.021)$ & 0.186 \\
Sex & n.s. $(0.057)$ & 0.154 \\
Region & n.s. $(0.790)$ & 0.021 \\
\hline
\end{tabular}

\section{Predicting an infection: use of single variables}

A second peak in CRP was considered to be indicative for an infectious complication. In the non-infection group, however, 15 out of 178 patients $(8.4 \%)$ presented a second peak, while in the infection group, 6 out of $14 \mathrm{did}$ (42.9\%). Subsequently, sensitivity for a second peak was $42.9 \%$, specificity $91.6 \%$, PPV $28.6 \%$ and NPV $95.3 \%$. A second peak was observed after $9.4 \pm 2.9$ days on average (non-infection group: $8.4 \pm 2.4$ days after surgery, infection group: $12 \pm 2.3$ days after surgery, $p=0.006$ ).

Another hint for an infection was the failure of CRP to decrease according to the abovementioned one-phase exponential decay (Fig. 2 a). In the non-infection group, 24 patients $(13.5 \%)$ did not decline according to the day 3 or day 4 cut-offs, while in the infection group, six patients (42.9\%) did not.

Combining the presence of a second peak with the failure to decrease, the sensitivity, specificity, PPV and NPV was $71.4 \%, 78.7 \%, 20.8 \%$ and $97.2 \%$, respectively. To further on improve the statistical value of these, another parameter, maximum CRP, was empirically selected. Calculating various cut-off values, a maximum of 225 was chosen to further improve the abovementioned algorithm. Assembling the existence of a second peak, failure to decrease and maximum CRP of more than $225 \mathrm{mg} / \mathrm{l}$, a sensitivity, specificity, PPV and NPV of $85.7 \%, 70.2 \%$, 18.4 and $98.4 \%$, respectively, was reached. Ultimately, we restricted the failure to decrease and counted the failure just if the maximum CRP was above $100 \mathrm{mg} / \mathrm{l}$. Along with the maximum CRP above $225 \mathrm{mg} / \mathrm{l}$, we reached a sensitivity, specificity, PPV and NPV of $92.9 \%, 78.2 \%, 25 \%$ and $99.3 \%$, respectively.

\section{Predicting an infection: binary logistic regression}

To establish a mathematical infection model with clinical applicability, binary logistic regression analyses for an infection were calculated on the imputed data with abovementioned parameters:
(1). The qualitative CRP value as used above (mean of CRP values of days 1 to 7 divided by maximum CRP divided; a value below 0.5 is considered indicative for an infection).

(2). Decline on day 3 or 4.

(3). Empirically determined CRP values: A sum of CRP in the days $1-7$ above $1200 \mathrm{mg} / \mathrm{l}$ and a mean CRP value from day 3 and 4 above $150 \mathrm{mg} / \mathrm{l}$.

With these parameters a binary logistic regression model showed that the entire model as each coefficient of the predictor was significant in predicting an infection (Nagelkerke $\left.R^{2}: 0.37, p<0.001\right)$ :

$y=-2.609+4.292 \times$ qualitative CRP -1.833

$\times$ decline day3or $4+3.132 \times$ empiric CRP

If the values of qualitative CRP value, failure to decline on day 3 and 4, and empirically determined CRP as stated above rise in 1 point, the likelihood of an infection will rise $4.2 \%, 1.8 \%$, and $2.6 \%$, respectively. Considering the Nagelkerke $R^{2}$ of 0.37 , the Cohen's effect size is very strong with 0.75 . To evaluate the approach, a ROC curve was modeled presenting an area under the curve (AUC) of 0.847 (Fig. 3).

Application of the binary logistic regression in our cohort resulted in values between 2.68 (I) and -5.44 (VII). The higher the resulting value of the binary logistic regression the higher the specificity and, subsequently, the lower the sensitivity.

\section{Patients with infections}

The fourteen patients with infections after dorsal spondylodesis were prominent due to a second peak or failure to decrease in 10 cases (71.4\%). The reoperation took place on average on day 10.71 ( \pm 3.28 days). In nine cases, a bacterium could be detected, while the other five cases displayed observable amounts of pus during revision surgery or persistent discharge, but no culturally or histologically traceable bacteria (Table 2).

\section{Discussion}

The early detection and multimodal treatment of postoperative spinal infections are the only way to ensure the reduction of these often prolonged and calamitous complications $[14,21]$. The proper and timely detection of these depicts a major intricacy for the operating surgeon. Throughout the last years, a number of screening tools have been assessed and validated. 
Fig. 3 ROC curve and table for sensitivity and specificity of binary logistic regression of selected values a ROC curve with an AUC of 0.847. b Sensitivity and specificity for selected results of the binary logistic regression, e.g., a sensitivity of $50 \%$ was paralleled by a specificity of $97.2 \%$, while a sensitivity of $85.7 \%$ went along with a specificity of $69.7 \%$

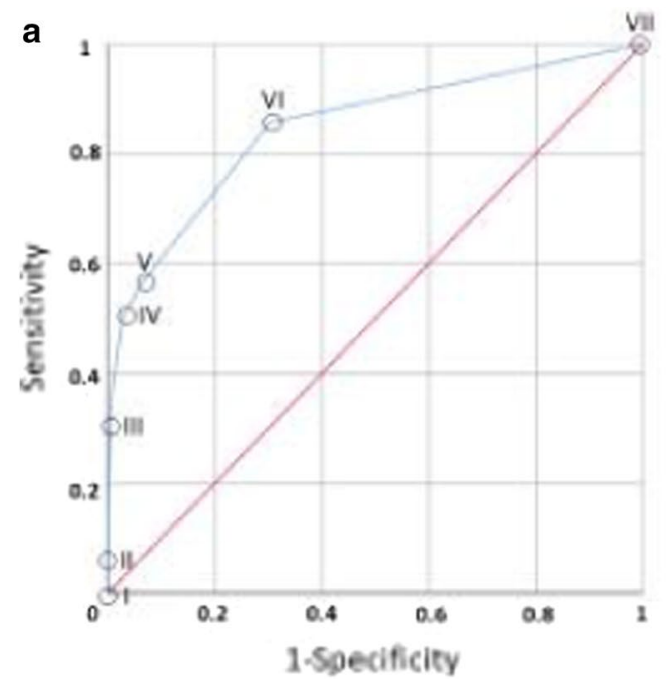

Table 2 Patients with infectious complications with underlying bacteria, CRP peak and predicted CRP on specific postoperative days

\begin{tabular}{|c|c|c|c|c|c|c|c|c|}
\hline Patient & Peak (day) & Peak (value) & $\begin{array}{l}\text { 2nd } \\
\text { peak } \\
\text { (day) }\end{array}$ & $\begin{array}{l}\text { Failure to } \\
\text { decrease? }\end{array}$ & Day of revision & Predicted CRP & Actual CRP & Species \\
\hline 1 & 2 & 201.3 & 9 & Yes & 12 th & 136.28 (day 3) & 137.2 & Serratia marcescens complex \\
\hline 2 & 14 & 224 & 9 & Yes & 9th & 151.65 (day 3) & 224.0 & $\begin{array}{l}\text { Enterobacter cloacae complex, } \\
\text { Staphylococcus aureus }\end{array}$ \\
\hline 3 & 3 & 102.6 & - & No & 10th & 69.46 (day 3) & 36.8 & / \\
\hline 4 & 4 & 290 & - & No & 15 th & 196.33 (day 3) & 102.5 & Escherichia coli \\
\hline 5 & 7 & 234 & 7 & Yes & 10th & 158.42 (day 3) & 167 & $\begin{array}{l}\text { Enterobacter cloacae complex, } \\
\text { Staphylococcus epidermidis }\end{array}$ \\
\hline 6 & 2 & 248 & - & Yes & 8th & 148.30 & 180 & $\begin{array}{l}\text { Staphylococcus epidermidis }+ \text { Staphy- } \\
\text { lococcus aureus }\end{array}$ \\
\hline 7 & 0 & 75.6 & 12 & No & 16th & 51.18 (day 3) & 26.6 & / \\
\hline 8 & 10 & 144.6 & 10 & No & 13th & 86.47 (day 4) & 22.5 & Propionibacterium acidum et acnes \\
\hline 9 & 3 & 115.3 & 7 & Yes & 11 th & 78.06 (day 3) & 96.5 & Escherichia coli \\
\hline 10 & 4 & 112.5 & - & Yes & 8th & 67.38 (day 4) & 92.3 & Staphylococcus epidermidis \\
\hline 11 & 15 & 93.2 & - & No & 9th & - & - & Escherichia coli \\
\hline 12 & 2 & 300 & 16 & Yes & 16 th & - & - & / \\
\hline 13 & 11 & 264 & - & Yes & 4th & 157.87 (day 4) & 246.3 & / \\
\hline 14 & 7 & 227.8 & - & No & 9th & 154.22 (day 3) & 64 & / \\
\hline
\end{tabular}

We created a mathematical approach to provide the clinician with a tool that uses broadly available parameters to make decisions regarding the probability of an infection after a dorsal spondylodesis with a relatively high sensitivity (92.9\%) and specificity (78.2\%), whereas the major drawback is the mixture of degenerative and traumatic cases in our cohort.

The gold standard for infection detection remains the microbiological isolation of the causing pathogen, which is often a time-consuming process and unfortunately an "a posteriori" method. The "raise for the surface" begins at the time of implantation, and early revision surgery in case of bacterial contamination, positively influences the outcome for the patient [22, 23]. Besides blood serum samples, instrument-based tools are implemented into the clinical case-finding procedure. Notwithstanding magnetic resonance imaging can be of help, it has not been established as screening tool due to high costs and metal artifacts [24].

Typically, WBC as well as erythrocyte sedimentation rate (ESR) and CRP are used to detect postoperative infection [25]. While in orthopedic and geriatric surgery WBC and ESR are well characterized, the CRP with the right cut-off values as well has established as an appropriate tool for early detection due to its high sensitivity [26-29].The occurrence 
of a "second peak" has been demonstrated to indicate an infectious complication in arthroplasty and microdiscectomy [27]. In spinal surgery, the natural kinetics of CRP has not yet been deeply examined compared to the course in infected patients.

A "peak" of CRP was detected on day 3 in our noninfectious group. In a study performed by Chung et al., the authors reported a peak on day 2 as well in 103 patients who underwent elective spinal surgery. As we pointed out that age, preoperative CRP value and the number of operated segments correlated significantly to the maximum CRP, age could be confirmed by Chung et al.[30]. This phenomenon was similarly described by Aono et al. while analyzing 168 patients and no infection who underwent a posterior lumbar interbody fusion, CRP peaking at day 4 (in 94\% of patients) and decreasing to $5 \mathrm{mg} / \mathrm{l}$ on day 14 [31].

In support of our data, Mok et al. analyzed 149 patients, mostly in the lumbosacral region, who were operated posteriorly and with a mean of 4.7 levels fusion. Different from that, we analyzed just one procedure and approach. They emphasized that postoperative kinetics follows a typical decline, while a "second rise or failure to decrease" was sensitive for infection resulting in a sensitivity and specificity (2nd peak or failure to decrease) of $71 \%$ and $51 \%$, respectively, which is exactly the same level of sensitivity in our study $(71.4 \%)$, while the here reported specificity was higher (79.8\%) [32]. The authors calculated a CRP kinetics curve, which follows a first-order elimination and predicted $70 \%$ of the variance of CRP values $\left(R^{2}=0.7011\right)$. In our study, the CRP values could be predicted by exponential regression with a comparable alignment $\left(R^{2}=0.7562\right)$.

Interestingly, Houten et al. demonstrated an influence of the number of operated levels on the maximum postoperative CRP value [33]. According to that, we show that the maximum CRP value is associated with the number of addressed segments. Since the incision lengths have not been collected in neither study, these can just serve as indirect parameters of the operative extent. Although this quantitative influence on the maximum CRP level is validated, an affectation of the infection rate has not been properly shown, while the literature on this subject is inconclusive $[34,35]$.

A further peak after discharge of patients cannot be excluded. However, patients of the non-infection group who developed a second peak did this in average on $8.4 \pm 2.4$ days after surgery and were discharged after $9.7 \pm 3.6$ days that is less than the average length of stay after lumbar spine surgery in Germany [36]. None of the patients from the noninfection group developed a wound infection after discharge within at least one year after surgery. In the end, the study shows that it is the combination of different CRP kinetics that is essential for a prediction of an infection with a high sensitivity (qualitative high CRP, failure to decline, and a second peak). In line with the strive for reduction of regular postoperative blood sampling [37, 38], the results of this study make more information available out of standard blood samplings in order to prevent further expensive and extensive diagnostics.

To our knowledge, a binary logistic regression with resulting sensitivity of $85.7 \%$ and specificity of $69.7 \%$ and a ROC curve with an AUC of 0.847 for predicting a SSI after spinal surgery have not been determined so far.

\section{Conclusions}

The study determined that specific kinetics of postoperative CRP is of great value detecting postoperative infections after open reduction and dorsal spondylodesis. On day 7 and 8 after the operation, the infectious group depicts significantly higher CRP values compared to the non-infectious group. With a second peak, restricted failure to decline and maximum CRP of more than 225 , a prognostic sensitivity and specificity of $92.9 \%$ and $78.2 \%$ to detect an infection was established, while a binary logistic regression leads to values of $85.7 \%$ and $69.7 \%$, respectively. A one-phase decay exponential regression predicts the "natural" course of CRP after initial peak $\left(R^{2}=0.7562\right)$. With this approach, focusing on typical kinetics of the CRP course caused by an infection, clinical decision making is supported by an inexpensive and easily assessed biomarker.

\section{Limitations}

The combination of traumatic and degenerative patients is the major drawback in our cohort. Although Suppl. Table 1 shows no differences between both groups in terms of the operated region or underlying reason of the operative procedure, the combination of all these may impair the power of our mathematical approach for either the traumatic or the degenerative patients due to a broader applicability.

The retrospective study design is prone to a selection bias. A weakness of this study is the low number of patients (178) and infections (14) as well as the exclusion of previously existing infectious diseases, which might be of special interest regarding the aging cohort of patients with spinal operative interventions. Despite the treatment and exclusion of common infections like pneumonia and urinary tract infections, these infections were just excluded if evident at the time of surgery, but could have existed. The duration of surgery and further patient characteristics (BMI, comorbidities) have not been assessed. The combination of traumatic and degenerative patients was needed since an isolated consideration would have impaired the power of our analyses. In regard to the binary logistic regression analysis using a forward inclusion approach it is noteworthy that this method 
is at higher risk to depend on researchers' knowledge and sensibility to the issues studied [20].

Supplementary Information The online version contains supplementary material available at(https://doi.org/10.1007/s00586-021-06782 $-8)$.

Funding Open Access funding enabled and organized by Projekt DEAL. DS was funded by the Deutsche Forschungsgemeinschaft (DFG, German Research Foundation) - 413501650.

Data availability The data are available from the corresponding author upon reasonable request.

\section{Declarations}

Conflict of interest The authors declare that they have no conflict of interest.

Consent for participate All research was performed in accordance with the principles expressed in the Declaration of Helsinki, all study participants voluntarily attended the study and gave informed consent.

Open Access This article is licensed under a Creative Commons Attribution 4.0 International License, which permits use, sharing, adaptation, distribution and reproduction in any medium or format, as long as you give appropriate credit to the original author(s) and the source, provide a link to the Creative Commons licence, and indicate if changes were made. The images or other third party material in this article are included in the article's Creative Commons licence, unless indicated otherwise in a credit line to the material. If material is not included in the article's Creative Commons licence and your intended use is not permitted by statutory regulation or exceeds the permitted use, you will need to obtain permission directly from the copyright holder. To view a copy of this licence, visit http://creativecommons.org/licenses/by/4.0/.

\section{References}

1. Agency for Healthcare Research and Quality (AHRQ) (2017) STATISTICAL BRIEF \#233. Overview of operating room procedures during inpatient stays in U.S. hospitals, 2014. https://www. hcup-us.ahrq.gov/reports/statbriefs/sb233-Operating-Room-Proce dures-United-States-2014.pdf. Accessed 02 May 2020

2. Deng H, Yue JK, Ordaz A, Suen CG, C Sing D (2019) Elective lumbar fusion in the United States: national trends in inpatient complications and cost from 20022014. J Neurosurg Sci. https:// doi.org/10.23736/S0390-5616.19.04647-2

3. Divi SN, Schroeder GD, Oner FC, Kandziora F, Schnake KJ, Dvorak MF, Benneker LM, Chapman JR, Vaccaro AR (2019) AOSpine-spine trauma classification system: the value of modifiers: a narrative review with commentary on evolving descriptive principles. Glob Spine J 9(1 Suppl):77S-88S. https://doi. org/10.1177/2192568219827260

4. Walker CT, Kakarla UK, Chang SW, Sonntag VKH (2019) History and advances in spinal neurosurgery. J Neurosurg Spine 31(6):775-785. https://doi.org/10.3171/2019.9.SPINE181362

5. Brown EM, Pople IK, de Louvois J, Hedges A, Bayston R, Eisenstein SM, Lees P (2004) Spine update: prevention of postoperative infection in patients undergoing spinal surgery. Spine 29(8):938945. https://doi.org/10.1097/00007632-200404150-00023
6. Dowdell J, Brochin R, Kim J, Overley S, Oren J, Freedman B, Cho S (2018) Postoperative spine infection: diagnosis and management. Global Spine J 8(4 Suppl):37S-43S. https://doi. org/10.1177/2192568217745512

7. Bišćević M, Bišćević S, Ljuca F, Smrke BU, Krupić F, Habul Ć (2014) Postoperative infections after posterior spondylodesis of thoracic and lumbal spine. Surg Spine Infect Psychiatr Danub 26(Suppl 2):382-386

8. Fang A, Hu SS, Endres N, Bradford DS (2005) Risk factors for infection after spinal surgery. Spine 30(12):1460-1465. https:// doi.org/10.1097/01.brs.0000166532.58227.4f

9. Janssen DMC, van Kuijk SMJ, d'Aumerie B, Willems P (2019) A prediction model of surgical site infection after instrumented thoracolumbar spine surgery in adults. Eur Spine J 28(4):775-782. https://doi.org/10.1007/s00586-018-05877-z

10. Schimmel JJP, Horsting PP, de Kleuver M, Wonders G, van Limbeek J (2010) Risk factors for deep surgical site infections after spinal fusion. Eur Spine J 19(10):1711-1719. https://doi. org/10.1007/s00586-010-1421-y

11. Weinstein MA, McCabe JP, Cammisa FP (2000) Postoperative spinal wound infection: a review of 2391 consecutive index procedures. J Spinal Disord 13(5):422-426. https://doi. org/10.1097/00002517-200010000-00009

12. Lethbridge LN, Richardson CG, Dunbar MJ (2020) Measuring surgical site infection from linked administrative data following hip and knee replacement. J Arthroplasty 35(2):528-533. https ://doi.org/10.1016/j.arth.2019.09.025

13. Muilwijk J, Walenkamp GHIM, Voss A, Wille JC, van den Hof S (2006) Random effect modelling of patient-related risk factors in orthopaedic procedures: results from the Dutch nosocomial infection surveillance network "prezies." J Hosp Infect 62(3):319-326. https://doi.org/10.1016/j.jhin.2005.08.006

14. Kalfas F, Severi P, Scudieri C (2019) Infection with spinal instrumentation: a 20-year, single-institution experience with review of pathogenesis, diagnosis, prevention, and management. Asian J Neurosurg 14(4):1181-1189. https://doi.org/10.4103/ ajns.AJNS_129_19

15. Lazzeri E, Bozzao A, Cataldo MA, Petrosillo N, Manfrè L, Trampuz A, Signore A, Muto M (2019) Joint EANM/ESNR and ESCMID-endorsed consensus document for the diagnosis of spine infection (spondylodiscitis) in adults. Eur J Nucl Med Mol Imaging 46(12):2464-2487. https://doi.org/10.1007/s0025 9-019-04393-6

16. Schuster JM, Rechtine G, Norvell DC, Dettori JR (2010) The influence of perioperative risk factors and therapeutic interventions on infection rates after spine surgery: a systematic review. Spine 35(9 Suppl):S125-S137. https://doi.org/10.1097/ BRS.0b013e3181d8342c

17. Choi MK, Kim SB, Kim KD, Ament JD (2014) Sequential changes of plasma c-reactive protein, erythrocyte sedimentation rate and white blood cell count in spine surgery : comparison between lumbar open discectomy and posterior lumbar interbody fusion. J Korean Neurosurg Soc 56(3):218-223. https:// doi.org/10.3340/jkns.2014.56.3.218

18. Foglar C, Lindsey RW (1998) C-reactive protein in orthopedics. Orthopedics 21(6):687-91 (quiz 692-3)

19. American Academy of Orthopaedic Surgeons. (2019) Diagnosis and prevention of periprosthetic joint infections. Clinical Practice Guideline. Published March 11, 2019. https://www.aaos. org/pjiguideline. Accessed 27 Aug 2020

20. Sperandei S (2014) Understanding logistic regression analysis. Biochemia medica 24(1):12-18. https://doi.org/10.11613/ BM.2014.003

21. Rauschmann M, Winking M, Arand M, Stücker R (2017) Wirbelsäule interdisziplinär. Operative und konservative Therapie, Schattauer, Stuttgart 
22. Garcia DR, Deckey DG, Zega A, Mayfield C, Spake CSL, Emanuel T, Daniels A, Jarrell J, Glasser J, Born CT, Eberson CP (2020) Analysis of growth and biofilm formation of bacterial pathogens on frequently used spinal implant materials. Spine Deform. https://doi.org/10.1007/s43390-020-00054-Z

23. Yin D, Liu B, Chang Y, Gu H, Zheng X (2018) Management of late-onset deep surgical site infection after instrumented spinal surgery. BMC Surg 18(1):121. https://doi.org/10.1186/s1289 3-018-0458-4

24. Rothman RH, Simeone FA, Garfin SR (2018) Rothman-Simeone and Herkowitz's the spine. Elsevier, Philadelphia

25. Wang Le, Yang B, Yin B, Zhang Z, Zhang L, Tang L, Lou A (2015) Clinical significance of PCT, CRP, ESR, WBC count as predictors in postoperative early infectious complications with fever after posterior lumbar internal fixation. China J orthop traumatol 28(1):66-70

26. Bingham JS, Hassebrock JD, Christensen AL, Beauchamp CP, Clarke HD, Spangehl MJ (2019) Screening for periprosthetic joint Infections with ESR and CRP: the ideal cutoffs. J Arthroplasty. https://doi.org/10.1016/j.arth.2019.11.040

27. Larsson S, Thelander U, Friberg S (1992) C-reactive protein (CRP) levels after elective orthopedic surgery. Clinical orthopaedics and related research (275):237-242

28. Neumaier M, Braun KF, Sandmann G, Siebenlist S (2015) C-reactive protein in orthopaedic surgery. Acta Chir Orthop Traumatol Cech 82(5):327-331

29. Zhao C, Wang J, Zhang H, Wang X, Sun B, Zhang K, Yang B (2019) Preoperative C-reactive protein level has a dose-response relationship with postoperative complications in elderly patients with femoral neck fracture. J South Med Univ 39(12):1511-1514. https://doi.org/10.12122/j.issn.1673-4254.2019.12.18

30. Chung YG, Won YS, Kwon YJ, Shin HC, Choi CS, Yeom J-S (2011) Comparison of serum CRP and procalcitonin in patients after spine surgery. J Korean Neurosurg Soc 49(1):43-48. https:// doi.org/10.3340/jkns.2011.49.1.43

31. Aono H, Ohwada T, Kaneko N, Fuji T, Iwasaki M (2007) The post-operative changes in the level of inflammatory markers after posterior lumbar interbody fusion. J Bone Joint Surg
89(11):1478-1481. https://doi.org/10.1302/0301-620X.89B11 .19478

32. Mok JM, Pekmezci M, Piper SL, Boyd E, Berven SH, Burch S, Deviren V, Tay B, Hu SS (2008) Use of C-reactive protein after spinal surgery: comparison with erythrocyte sedimentation rate as predictor of early postoperative infectious complications. Spine 33(4):415-421. https://doi.org/10.1097/BRS.0b013e318163f9ee

33. Houten JK, Tandon A (2011) Comparison of postoperative values for C-reactive protein in minimally invasive and open lumbar spinal fusion surgery. Surg Neurol Int 2:94. https://doi. org/10.4103/2152-7806.82575

34. O'Toole JE, Eichholz KM, Fessler RG (2009) Surgical site infection rates after minimally invasive spinal surgery. J Neurosurg Spine 11(4):471-476. https://doi.org/10.3171/2009.5.SPINE 08633

35. Tan JH, Liu G, Ng R, Kumar N, Wong H-K (2018) Is MIS-TLIF superior to open TLIF in obese patients?: a systematic review and meta-analysis. Eur Spine J 27(8):1877-1886. https://doi. org/10.1007/s00586-018-5630-0

36. Herren C, Aghayev E, Kaulhausen T, Roeder C, Meyer F, Siewe J, Sobottke R (2014) Einflussfaktoren auf die Verweildauer in der Wirbelsäulenchirurgie : Eine Datenanalyse des Deutschen Wirbelsäulenregisters (Influencing factors on the length of stay in lumbar spine surgery : analysis of the German spine registry). Der Orthopade 43(12):1043-1051. https://doi.org/10.1007/s0013 2-014-3033-4

37. Faulkner A, Reidy M, McGowan J (2017) Should we abandon routine blood tests? BMJ. https://doi.org/10.1136/bmj.j2091

38. Wu X-D, Zhu Z-L, Xiao P-C, Liu J-C, Wang J-W, Huang W (2020) Are routine postoperative laboratory tests necessary after primary total hip arthroplasty? J Arthroplasty. https://doi. org/10.1016/j.arth.2020.04.097

Publisher's Note Springer Nature remains neutral with regard to jurisdictional claims in published maps and institutional affiliations. 